\title{
As boas práticas com TIC e a utilidade atribuída pelos alunos recém-integrados à universidade'
}

María Carmen Ricoy"

Maria João V. S. Couto"

I- Esta contribuição faz parte de um projeto de investigação ( $n^{0}$ de referência: "INOU12-14"; Resolução Reitoral de 7/5/2012) financiado pela Universidade de Vigo e pela Deputação de Ourense (Espanha).

II- Universidade de Vigo, Ourense, Galiza, Espanha.

Contatos: cricoy@uvigo.es;

mjoaocouto@uvigo.es

\section{Resumo}

As Tecnologias da Informação e Comunicação (TIC) marcam as dinâmicas de trabalho dos diferentes contextos profissionais, e o âmbito educativo não é uma exceção. Nesta investigação, pretende-se conhecer a percepção que têm os alunos recém-integrados ao ensino universitário sobre as boas práticas educativas com as TIC. Para tanto, analisou-se o conteúdo de relatos dos alunos, nos quais plasmam sua reflexão sobre as experiências e ideias prévias no âmbito da temática em causa. 0 estudo de caso abordou-se a partir de um enfoque qualitativo que se enquadra na investigação narrativa. A amostra é composta por 55 alunos com idades entre 18 e 37 anos que frequentam o $1^{\circ}$ ano do Grau em Educação Social na Universidade de Vigo (Espanha). Como resultados e principais conclusões, salienta-se que a simples utilização das TIC é associada pelos participantes às boas práticas, sem questionar a combinação de seu uso com o de estratégias didáticas de tipo inovador. Descobre-se que eles atribuem as boas práticas com TIC ao uso de dispositivos e aplicativos bastante atuais. Os participantes identificam diferentes benefícios em seu uso relativamente a: acesso à internet, comunicação, publicação e difusão de conteúdos numa multitude de formatos. Já como obstáculos, destacam o elevado custo econômico de alguns dispositivos, as dificuldades técnicas, a distração que podem produzir, assim como a perda de contato pessoal e de tempo. Também são capazes de extrapolar a utilização do que consideram boas práticas com TIC a algum aspecto do trabalho de sua futura profissão.

\section{Palavras-chave}

Tecnologias da informação e comunicação - Boas práticas Inovação educativa - Educação superior. 


\title{
Best practices with ICT and the value attributed by the students newly integrated in university'
}

María Carmen Ricoy"

Maria João V. S. Couto"

\begin{abstract}
The Information and Communication Technologies (ICT) mark the work dynamics of the different contexts and the field of education is not an exception. This research aims to understand the perception that students recently integrated in university education have on best educational practices with ICT. In particular we analyzed the content of reports in which students express their reflections about experiences and previous ideas on the theme. The case study was addressed from a qualitative approach that fits in the narrative inquiry. The sample consists of 55 students aged between 18 and 37 years attending the first year of Social Education Bachelor's degree at University of Vigo (Spain). As main results and conclusions we must note that the mere use of ICT is linked by participants to best practices without questioning the combination of its use with that of innovative teaching strategies. It was found that they attach best practices with the use of very updated ICT devices and applications. Participants identify different benefits in its use related to: internet access, communication, publication and dissemination of content in a multitude of formats. As for obstacles, they highlight the high economic cost of some devices, technical difficulties, the distraction that they can produce, as well as the loss of personal contact and time. They are also able to extrapolate the use of what they consider best practices with ICT to some aspect of the work of their future profession.
\end{abstract}

\section{Keywords}

Information technology and communication - Best practices Educational innovation - Education.

I- This contribution is part of a research project, reference number: "INOU12-14" (Rector's Resolution of 7/5/2012). It was funded by the University of Vigo and the Provincial Deputation of Ourense (Spain).

II- University of Vigo, Spain. Contacts: cricoy@uvigo.es; mjoaocouto@uvigo.es 
As Tecnologias da Informação e Comunicação (TIC) são dispositivos que podem promover mudanças muito importantes nas diferentes facetas da vida das pessoas a partir das práticas, dos serviços e do conhecimento que facilitam. Além das bibliotecas, a internet converteu-se no espaço preferencial para a procura de informação, em particular para os estudantes universitários. As TIC são muito úteis no processamento, no armazenamento e na transmissão de informação. Nesse sentido, Coelho, Rosário e Ferreira (2012) também consideram que elas são instrumentos essenciais e que impulsionam transformações, atuando sobre os indivíduos e produzindo modificações físicas, cognitivas e sociais.

Afortunadamente, hoje em dia podemos dizer que, em geral, a nova tecnologia já está ao alcance dos alunos mais novos antes de frequentarem o ensino universitário (FERREIRO, 2011) e também daqueles que cursam a educação superior. Cada vez em maior medida, os dispositivos digitais proliferam particularmente entre os estudantes universitários, sendo necessários tanto em sua formação acadêmica quanto no exercício profissional futuro. Para isso, é importante aprofundar-se no uso dessa tecnologia na qual se requer uma boa prática, já que, assim como ocorre na educação, a ela estão associadas grandes expectativas sociolaborais e de desenvolvimento. A utilização das TIC requer saber fazer a partir do ser e condiciona o saber estar para conviver com os demais.

A finalidade central deste trabalho é indagar sobre as experiências, as crenças e o conhecimento prévio de boas práticas com as TIC que têm os estudantes do $1^{\circ}$ ano dos estudos universitários. Isso permitirá contextualizar e, em maior medida, adaptar a planificação do ensino com futuras turmas, assim como integrar as TIC ao currículo acadêmico a partir da percepção dos estudantes. Para nos aprofundarmos no referido, como objetivos específicos consideram-se os seguintes:

- determinar os equipamentos fixos ou móveis e/ou os aplicativos digitais que os alunos associam às boas práticas com as TIC;
- descobrir os benefícios ou a utilidade que atribuem às boas práticas com as TIC;

- identificar os inconvenientes que encontram nas boas práticas com as TIC;

- conhecer a extrapolação sobre o uso de boas práticas com as TIC que os estudantes projetam no campo de trabalho da futura profissão.

Todos esses propósitos estão encaminhados para a melhoria do processo de ensino-aprendizagem a partir da inclusão das TIC. Além disso, supõem um ponto de partida para favorecer a renovação educativa baseada na integração acadêmica das TIC.

\section{As TIC e as boas práticas pedagógicas}

Nos centros de educação superior, as infraestruturas e os novos equipamentos tecnológicos foram incrementados na última década. O desenvolvimento desse tipo de recurso é vertiginoso. Apesar disso, no âmbito educativo, o uso de boas práticas avança lentamente. De fato, em muitos casos, a aplicação das TIC encontra-se imersa em dinâmicas tradicionais. Por isso, coincidimos com De Pablos e Jiménez (2007) em que, para fazer frente à referida situação, também é preciso o desenvolvimento de novas competências nos professores, assim como a utilização de metodologias inovadoras. Tudo isso a partir do papel que têm as universidades de empreender políticas favoráveis e da função dos docentes na capacitação do uso das TIC, além da produção e difusão de conhecimento para um melhor aproveitamento dos recursos tecnológicos (VICENTINI, 2012).

No âmbito educativo, o termo inovação refere-se à incorporação de componentes novas que permitam melhorar, produzir mudanças entendidas como elemento de renovação pedagógica. Area, San Nicolás e Fariña (2010) ressaltam que a inovação acadêmica traduz-se na criação e disponibilização de materiais com as TIC e enfatizam a promoção da interação e da comunicação a partir das ferramentas das 
redes sociais. Verdadeiramente é necessário impulsionar esses últimos aspectos, mas sem descuidar dos componentes didáticos renovadores. De fato, a partir do contexto educativo, é possível pensar em

[...] elementos definidores da sala de aula virtual, os quais podem fazer dela o cenário de uma experiência didática única, prazerosa, efetiva, eficaz e totalmente condizente com a dinâmica da sociedade da informação. Esses elementos definidores, dada sua natureza revolucionária, indicam a própria engrenagem do processo de mudança aqui discutido. São eles os conceitos de comunidade de aprendizagem em rede, de trabalho colaborativo virtual, de horizontalização da relação educativa, de materiais didáticos dinâmicos e de mediação pedagógica fundamentada na interatividade. A adoção desses conceitos impõe uma nova dinâmica para a relação educativa virtual, distanciada de procedimentos tradicionais já inoperantes na educação tradicional e de caminhos de massificação da formação e de determinismo tecnológico. (SANTOS, 2011, p. 317-318)

No contexto acadêmico, a expressão boas práticas com TIC é sinônimo do bem fazer didático e de uma práxis inovadora. Nesse âmbito, refere-se à possibilidade de inovar com os novos recursos tecnológicos, a partir da integração de estratégias didáticas dinâmicas e interativas que propiciem a aprendizagem significativa nos alunos. Seu objetivo é alcançar bons resultados acadêmicos e outros de elevado valor educativo, assim como a satisfação dos implicados. De fato, Coll, Mauri e Onrubia (2008) relacionam a aprendizagem dos alunos com a qualidade das práticas que desenvolvem. Na linha do referido, os seguintes aspectos favorecem o desenvolvimento de práticas inovadoras com TIC: disponibilidade de novos dispositivos tecnológicos, acesso à internet, bem fazer dos professores e implicação ativa dos alunos.
Para Bates (2004), as boas práticas em educação estão associadas ao uso de métodos inovadores, respondem a experiências planejadas de antemão e são desenvolvidas de modo sistemático. Salinas (2004) considera que os eixos vertebrais da inovação educativa estão relacionados diretamente com a planificação docente, com as ações de melhoria da práxis e com a incorporação das TIC. Nesse sentido, entende-se que o uso dos recursos digitais como ferramentas de aprendizagem pode ser um catalisador para a transformação educacional (RICOY; SEVILLANO; FELIZ, 2011; YANG, 2012). De fato, na atualidade, os profissionais da educação são conscientes da repercussão que tem a aplicação dessas práticas com aparelhos tecnológicos nos níveis educativos regulados e também nos âmbitos da educação não formal.

Tanto no ensino não universitário quanto no superior, procurar o sucesso acadêmico dos estudantes tem que constituir uma prioridade dos profissionais da educação e dos políticos. Vanderlinde, Van Braak e Dexter (2012) indicam que os professores, investigadores e políticos promovem, em alguma medida, a integração das TIC a partir dos planos de estudo. Além disso, para assumir o repto de delinear metodologias de intervenção capazes de produzir os efeitos desejados de forma consistente, é necessário contar com os investimentos econômicos oportunos.

Também cabe às comunidades educativas um papel central no combate à fenda digital, disponibilizando os meios e o desenvolvimento de competências nos alunos para contrariar as desigualdades existentes, por meio da promoção dos novos recursos tecnológicos e da integração de estratégias de aprendizagem inovadoras. É de considerar, como manifestou Molina (2003), que as TIC trazem grandes oportunidades, mas também ameaças ao desenvolvimento de países e coletivos ou pessoas com menos recursos. Nesse sentido, é de salientar a importância de um movimento global promotor da e-inclusão. 0 fenômeno da globalização está sustentado num conjunto de processos atribuídos à revolução 
tecnológica da informática e das comunicações, é promovido pelo potencial econômico dos países industrializados e influencia a esfera privada e pública do social, do cultural e do político. Adicionalmente, relativiza os conceitos de espaço, tempo e mobilidade, implicando o progresso de alguns e a desventura de muitos (COELHO, 2010).

Além de suscitar a mudança dos recursos educativos, há que insistir que a penetração das TIC no processo de ensino-aprendizagem requer uma utilização inovadora na tarefa didática. A partir da formação inicial, o ensino superior deve fomentar nos futuros profissionais a aquisição das habilidades, das destrezas e dos conhecimentos exigidos de forma geral nos contextos de trabalho. Isso permitirá dotar os estudantes universitários das competências digitais reclamadas pelas atuais dinâmicas sociolaborais.

As TIC podem ser agentes de transformação na universidade e a partir dela sempre que passem pela alteração da práxis tradicional e se promovam preferencialmente por meio de métodos colaborativos, com novas formas de interação em ambientes físicos e virtuais. De fato, o desenvolvimento do processo formativo exige a combinação dos espaços presenciais com os virtuais (DÍEZ GUTIÉRREZ, 2012; DIRCKINCK-HOLMFELD; LORENTSEN, 2003). Esse aspecto também é necessário considerar para dar respostas adequadas, a partir de uma nova configuração pedagógica na educação superior.

A integração de boas práticas no currículo universitário desperta especial interesse, em particular no marco de adaptação da docência ao Espaço Europeu de Educação Superior (EEES), na medida em que condiciona e repercute, entre outros aspectos, na qualidade do processo formativo. Além disso, é imprescindível basear a construção de aprendizagem na atividade do estudante, encaminhando-a para o desenvolvimento das competências pertinentes. Nesse sentido, tem que ganhar relevância o papel do aluno como aprendiz, a partir do uso de estratégias metodológicas capazes de outorgar-lhe mais responsabilidade e protagonismo (CANALES; MARQUÉS, 2007).

A identificação de boas práticas com TIC pelos alunos da educação superior permite-lhes refletir e indagar sobre elas, assim como previsivelmente transferi-las no futuro ao contexto profissional por meio de uma visão crítica. Nesse caso, ganham especial relevância as vivências experimentadas e as crenças prévias; além disso, tal identificação possibilita melhorar o grau de sensibilização e a resolução perante determinadas problemáticas ou aproximar os alunos aos âmbitos de trabalho da profissão. Por outra parte, essa análise favorece nos docentes do ensino superior a planificação da práxis e a implementação futura, bem como permite a difusão à comunidade científica e educativa. Também pode contribuir, de acordo com Hong e Songan (2011), para otimizar a execução e a gestão de programas e práticas futuras com as TIC na educação superior.

\section{Metodologia de pesquisa}

Esta investigação insere-se numa mais ampla, embora, por questões de espaço, a que se aborda no presente artigo centre-se numa parte. 0 trabalho aqui recolhido desenvolve-se mediante uma metodologia qualitativa. Em concreto, enquadra-se na investigação narrativa (narrative inquiry). Esse tipo de metodologia possibilita o conhecimento da situação analisada a partir de sua própria idiossincrasia (GONZÁLEZ CUBILLÁN, 2009).

0 contributo feito focaliza-se num estudo de caso de caráter descritivo-compreensivo que pretende atribuir significado a partir da análise e da interpretação decorrente das narrativas dos participantes. Isso resulta factível mediante a descrição extensiva, assim como pela análise sistemática e em profundidade que se realiza da informação recolhida. Yin (2005) entende que um estudo de caso consiste numa investigação empírica interessada num fenômeno dentro 
do real. De fato, este trabalho abordou-se de acordo com tal perspectiva em congruência com a temática e o contexto de estudo tratado.

Em educação é possível fazer referência ao estudo de caso com um estudante, um professor, os alunos de uma aula, escola ou comunidade. 0 que se promoveu é de tipo instrumental e centra-se na análise de uma parte do tópico objeto da investigação, com os estudantes de uma turma (STAKE, 2007). Sua tipologia permite estudar a temática abordada a partir da visão global que têm os participantes e por meio de sua própria singularidade. Com base na perspectiva definida, enfatiza-se a importância das contribuições diretas dos implicados, da técnica utilizada na coleta da informação e do tipo de análise aplicada (LECOMPTE; PREISSLE, 1993).

\section{Participantes}

Em sintonia com o tipo de estudo desenvolvido, a amostra considerada é reduzida para possibilitar sua análise em profundidade, pois não se trata de seguir procedimentos estatísticos. Ela é composta por um total de 55 alunos do Grau em Educação Social da Faculdade de Ciências da Educação na Universidade de Vigo (Espanha). Desses estudantes, seis são do gênero masculino e 49 do feminino. A desproporção está justificada pela composição inicial do grupo que frequentava o curso e que em geral ocorre nos cursos de educação. As idades estavam compreendidas entre os 18 e os 37 anos, sendo a média de idade de 21 anos (tabela 1).

Tabela 1 - Distribuição da idade e do gênero dos participantes

\begin{tabular}{|c|c|c|c|c|c|c|c|c|c|c|c|c|}
\hline Idade & 18 & 19 & 20 & 21 & 22 & 23 & 24 & 26 & 27 & 28 & 37 & \multirow{3}{*}{ 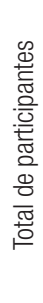 } \\
\hline Gênero & 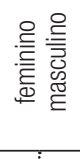 & 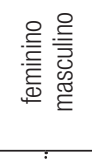 & 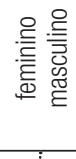 & 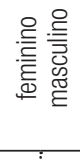 & 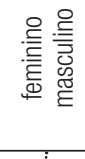 & 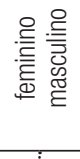 & 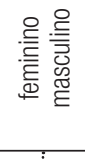 & 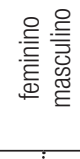 & 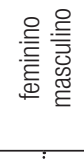 & 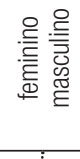 & 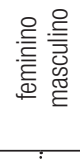 & \\
\hline N. de participantes & $7 \vdots 1$ & $13 \vdots 2$ & $5 \vdots 0$ & $2 \vdots 0$ & $12 \vdots 2$ & 5 & $1 \vdots 0$ & $2 \vdots 0$ & $0 \vdots 1$ & $1 \vdots 0$ & $1 \vdots 0$ & \\
\hline$\Sigma$ & 8 & 15 & 5 & 2 & 14 & 5 & 1 & 2 & 1 & 1 & 1 & 55 \\
\hline
\end{tabular}

Fonte: Dados da pesquisa.

Mais de metade dos alunos $(n=29)$ que constituíram a amostra tinha 19 e 22 anos, e são unicamente oito os que ingressaram na universidade com a idade mínima (18 anos) requerida para cursar os estudos universitários na Espanha. Excepcionalmente encontramos algum estudante a frequentar 0 $1^{\circ}$ ano da universidade com idade entre $26 \mathrm{e}$ 37 anos, ainda que esse fato não seja habitual no ensino superior presencial na Espanha. É comum que os alunos com mais de 25 anos acedam a esses estudos na Universidade Nacional de Educação a Distância, na qual a média de idade é elevada.

\section{Técnica de recolha da informação}

A técnica utilizada para a coleta da informação foi o relato autobiográfico temático, descrito na primeira pessoa por cada participante. Essa técnica permite desenvolver uma história coerente e centrada num propósito determinado, circunscrevendo-a ao tópico de estudo por meio da formulação aberta da petição aos implicados. Os relatos autobiográficos consistem numa narração retrospetiva. No caso que nos ocupa, os alunos narraram suas recordações, crenças, percepções e opiniões resultantes das experiências próprias e/ou de outras conhecidas 
sobre as boas práticas com TIC, atribuindo-lhes um significado. A informação obtida a partir desse instrumento dificilmente seria acessivel com a utilização de outros meios, sendo, além disso, um veículo idôneo para tornar explícito o pensamento dos próprios implicados.

0 guião do relato planificou-se ad hoc com a finalidade de responder aos objetivos definidos para uma parte da investigação abordada. Esse protocolo esteve precedido da identificação pessoal, com a garantia da proteção dos dados de caráter privado. No relato sobre o tópico central de estudo, a questão definida foi formulada de forma aberta para conjugar a espontaneidade dos participantes com a amplitude de sua narração. Para desencadear a descrição, a reflexão e a valoração sobre a temática objeto de análise, solicitou-se aos alunos a partir do seguinte: "Indica e comenta as boas práticas na educação com as Tecnologias da Informação e Comunicação que tiveste a oportunidade de realizar ou que conheces, considerando a sua repercussão ou utilidade”.

Para a validação da construção do instrumento, recorreu-se aojuízo de especialistas, submetendo-se o enunciado inicial do relato à análise de cinco entendidos (três mulheres e dois homens) em metodologia qualitativa. A seleção atendeu ao grau de especialização tanto na temática em causa quanto na elaboração desse tipo de técnica de recolha de informação. Os responsáveis por esse trabalho foram docentes e investigadores altamente qualificados de cinco universidades espanholas (Universidade de Alcalá de Henares, Universidade de Granada, Universidade de Murcia, Universidade Nacional de Educação a Distancia e Universidade de Vigo). A partir de seus juízos analíticos e valorativos, reconstruiu-se a redação inicial da formulação do relato. Esse conselho de especialistas permitiu maior adequação e maior clareza do enunciado da questão apresentada, possibilitando compreensão ao coletivo a que se dirigiu. Além disso, contribuiu para que os participantes desenvolvessem narrativas que respondessem às finalidades do estudo.

\section{Procedimento de recolha e análise da informação}

Os relatos promovidos nos estudantes tiveram uma finalidade pedagógica e outra expressa para a recolha da informação. A partir desse fato é possível apresentar à comunidade científica uma contribuição com resultados e conclusões valiosas. A recolha de dados foi impulsionada por uma professora (coautora deste artigo) por meio da técnica do relato numa turma a partir de uma disciplina acadêmica da titulação do Grau em Educação Social.

Para o desenvolvimento do relato de modo autônomo e individual pelos estudantes fora da sala de aula, foi prevista uma dedicação de 60 a 90 minutos. Os participantes realizaram essas narrativas em formato escrito e em suporte digital num programa de processamento de textos. Depois de um debate promovido pela docente, incluiram-nas nos e-portfólios de aprendizagens seguindo as indicações. Essa informação, que fora depositada na plataforma de teleformação Claroline-Faitic (colocada à disposição dos alunos e professores pela Universidade de Vigo) nos referidos e-portfólios, foi retomada no final do período letivo de 2012, tendo sido analisada em profundidade.

Para a análise de conteúdo aplicada aos documentos produzidos, procedeu-se primeiramente ao inventariado independente dos diferentes arquivos, atribuindo aos relatos um número correlativo de 1 a 55 em função de sua totalidade. Posteriormente esses textos foram convertidos do formato Word para o de Rich Text Format (RTF). Com a finalidade de empreender o processo de análise de conteúdo, a partir de uma importação individualizada, integraram-se no programa de Analysis of Qualitative Data (AQUAD), versão 6.0 para texto. Com essa abordagem, a informação recolhida tornar-se-ia manejável por meio do sistema de codificação categorial aplicado, que adicionalmente permitiria interpretá-la, responder aos objetivos e compreender as dimensões de estudo.

A categoria principal de análise ou de primeiro nível foi definida a partir da questão 
sobre o tópico colocado no protocolo do relato. Para nos aprofundarmos no conteúdo, procedeuse à concretização da codificação, definindo as subcategorias (de segundo e terceiro nível). Para isso, parte-se dos propósitos específicos do estudo e da informação obtida por meio de ideias com sentido que permitem concretizar as unidades de análise (FELIZ, 2012; FLICK, 2005). Esse procedimento facilita a redução dos dados brutos através de subcategorias representativas (SARRADO; PRUNA; LÓPEZ, 2007).

Como se adiantou, o processo de subcategorização (de segundo nível) derivou da informação recolhida, sendo atribuídos os códigos que se associam aos respectivos núcleos com sentido, a partir dos objetivos específicos. Posteriormente, aprofundou-se no seu conteúdo vinculando novamente a cada ideia relevante outro subcódigo e representando a correspondente subcategoria (terceiro nível). Por um lado, isso permitiu criar um sistema aglutinador do conteúdo principal facilmente interpretável; por outro, através das subcategorias encontradas em cada dimensão foi possível indagar sobre os objetivos específicos.

0 software utilizado também permite exportar posteriormente os dados ao programa Excel para a elaboração de gráficos e tabelas com as subcategorias de resultados. Essas representações são de utilidade para conhecer o nível de preponderância atribuída às subcategorias e apresentar evidências visuais e icônicas sobre os resultados obtidos. Com isso, não se pretende dar um enfoque quantitativo ao que é um estudo integralmente qualitativo.

No que respeita à frabilidade dos resultados apresentados, é de indicar que está associada à sistematização seguida no desenvolvimento do processo de investigação, em particular ao rigor alcançado com a análise abordada. Além disso, consideram-se os elementos metodológicos essenciais: estruturou-se e tutelou-se oportunamente a fase de recolha de informação, defıniu-se o procedimento para desenvolver a análise de conteúdo e apresentaram-se evidências consistentes a partir dos resultados expostos (HERNÁNDEZ; FERNÁNDEZ; BAPTISTA, 2006). É de salientar que se recebeu a assessoria de um especialista externo para determinar os critérios mais idôneos para o estabelecimento das subcategorias de partida, associando-as aos distintos níveis da análise, fato que também permite reforçar a consistência dos resultados obtidos.

\section{Resultados}

Como expressamos, a partir da percepção dos participantes, as boas práticas com TIC (que representam a categoria de primeiro nível) são refletidas levando em consideração as dimensões de análise que derivam dos objetivos específicos. A determinação das subcategorias de segundo nível é a seguinte:

- dispositivos ou aplicativos associados às boas práticas com TIC pelos alunos;

- utilidades ou benefícios que eles relacionam com as boas práticas digitais;

- obstáculos atribuídos às boas práticas com TIC; - extrapolação das boas práticas tecnológicas à futura profissão.

As quatro dimensões de análise referidas encabeçam cada subgrupo desta epígrafe. Para que o leitor tenha uma melhor compreensão dos resultados obtidos, ilustram--se com a apresentação de gráficos e tabelas, bem como com diferentes excertos dos relatos (neste trabalho, traduziram-se seus textos para a língua portuguesa por ser o idioma no qual se apresenta o artigo). Das narrativas indicam-se o número do relato correspondente e o gênero do participante (exemplo: $\mathrm{R}_{36}$, feminino).

\section{Dispositivos ou aplicativos associados às boas práticas com TIC}

Como exemplo de boas práticas com TIC, os alunos apresentam o uso de determinados dispositivos e aplicativos: computadores de mesa e portáteis, alguns periféricos (câmaras, scanner e pendrive), smartphone e seus programas (por 
exemplo: WhatsApp), livro eletrônico, software genérico, quadro interativo, salas de chat, plataformas educativas (por exemplo: Moodle e Claroline-Faitic), vídeo digital/documentos multimídia, ferramentas da web 2.0 para publicar e difundir conteúdos on-line (em blogs, páginas web e Google Drive) e e-mail (gráfico 1).

Como se depreende dos resultados apresentados, os participantes identificam as boas práticas com TIC com dispositivos ou aplicativos digitais bastante atuais, que lhes resultam atrativos e que contam com potencial inovador. Alguns desses recursos (computadores, smartphone e suas aplicativos) têm já um importante uso em contextos informais. Outros aparelhos estão mais diretamente relacionados com as práticas acadêmicas (quadro interativo, salas de chat e plataformas educativas de teleformação).

Gráfico 1 - Dispositivos/aplicativos para boas práticas com TIC

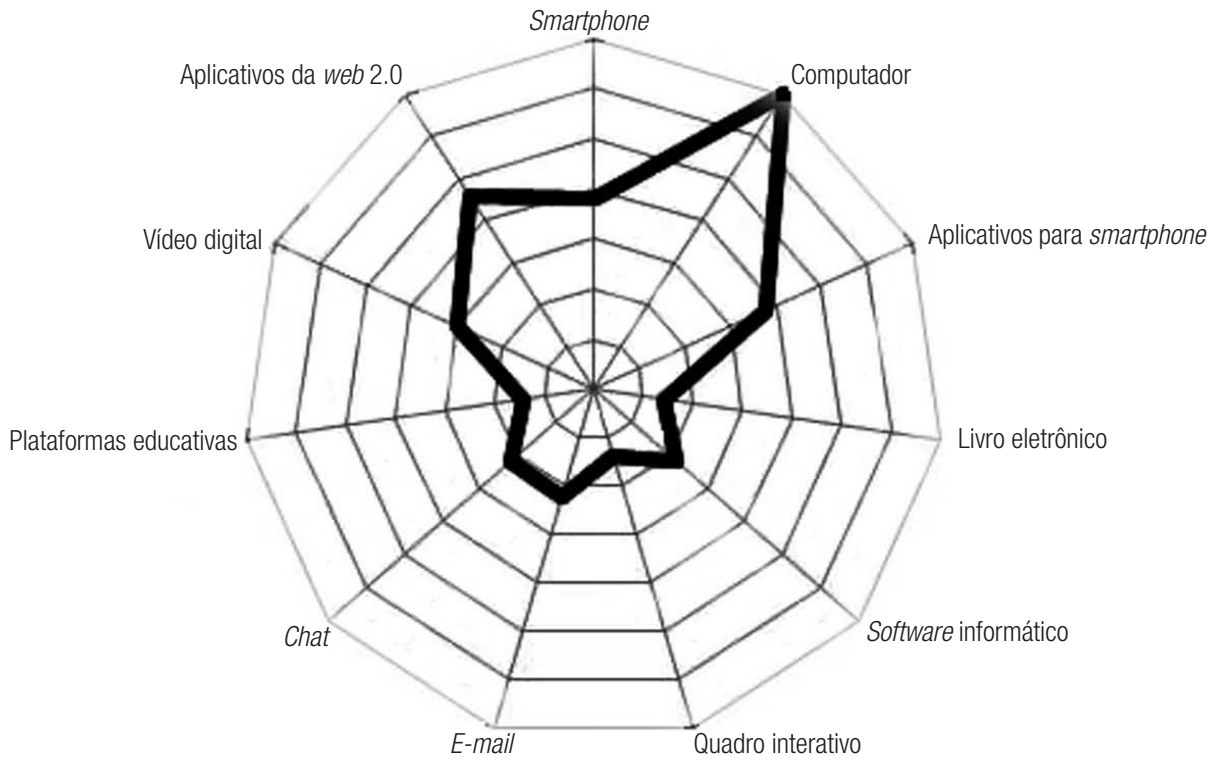

Fonte: Dados da pesquisa.

Um grupo de participantes relaciona as boas práticas com TIC a diversos aplicativos disponíveis on-line. Como exemplo, referem-se à utilização de sistemas on-line para partilhar arquivos, como o Google Drive. Essa plataforma gratuita é utilizada essencialmente para disponibilizar documentos que, pelo seu tamanho, são difíceis de anexar numa mensagem de correio eletrônico e de editar, se houver a necessidade, ou para realizar trabalho colaborativo.

As possibilidades do e-mail são reconhecidas como de grande interesse para a comunicação assíncrona, por permitirem aos participantes trocar facilmente certo volume de conteúdos em diferentes formatos, discutir ou realizar avisos com caráter formal ou informal. Globalmente, essa ferramenta é considerada muito adequada para facilitar o fluxo de informação entre professores e alunos. Como exemplo, veja-se o seguinte extrato:

No princípio abri a conta no Hotmail meramente para falar com amigos/as, mas agora a considero fundamental, uma vez que é uma ferramenta básica para comunicarmos de maneira rápida e fácil, assim como para enviar e receber informação. $\left(\mathrm{R}_{18}\right.$, feminino) 
Noutras narrativas, os participantes relacionam as boas práticas com TIC à comunicação que se pode estabelecer utilizando distintos aplicativos e software específico. Em concreto, em contextos on-line, entre outros, os alunos citam a vídeochamada. Uma aluna indica:

Um dos professores que tive, que é uma pessoa surda, explicou-nos que usava a webcam no messenger para falar na língua gestual. Não sabemos por que, mas não nos tinha ocorrido essa opção para pessoas surdas. $\left(\mathrm{R}_{27}\right.$, feminino)

Outro recurso que os alunos consideram inovador consiste num equipamento tecnológico para pessoas com limitações no âmbito da comunicação sonora. Referem que, com um pequeno número de imagens (por meio de distintos ícones), o utilizador pode comunicar de forma autônoma um amplo vocabulário sem ter que aprender e navegar por meio de um grande conjunto de imagens. Nesse sentido, declara uma estudante:

Um exemplo de boa prática com TIC parece-me o comunicador que funciona com o sistema MINSPEAK. É uma linguagem visual muito simples e bastante utilizada em comunicação aumentativa. Com esse comunicador, os meninos autistas ou que padecem de tetraparesia espástica, sem comunicação verbal, que apenas contam com comunicação gestual, conseguem comunicar-se com grande facilidade. $\left(\mathrm{R}_{3}\right.$, feminino)

A utilização das plataformas educativas (Moodle ou Claroline-Faitic) é referida como exemplo de boas práticas com as TIC. Consideram que esse recurso de e-learning, disponível em muitos centros educativos, reúne um conjunto variado de potencialidades úteis para o processo de ensino-aprendizagem. Os participantes ressaltam que no mesmo cenário é possível dispor de conteúdos em distintos formatos (texto, áudio ou multimídia) e tipologias (apontamentos, exercícios, fichas de trabalho, apresentações, vídeos, link e testes). Também manifestam que é possível dinamizar simultaneamente o desenvolvimento de diversas atividades on-line (fóruns, wikis, chat, e-diários, e-portfólios ou exames) relacionadas com o envio de trabalhos. Os implicados neste estudo valorizam positivamente que esses recursos apoiem o trabalho presencial do professor e do aluno e permitam o ensino e aprendizagens a distância de forma virtual. A esse respeito, uma participante narra:

A experiência que me pareceu uma boa prática com Moodle baseou-se na criação de uma aula virtual. Havia a opção de comentar as dúvidas mediante o chat ou o fórum. [...]. Permitiu a criação de wikis numa disciplina em que tínhamos que procurar o significado de vários latinismos e topônimos e depois enviá-los através da plataforma. Também se podia subir ou descarregar muito conteúdo digital: os apontamentos, vídeos e PowerPoint. $\left(\mathrm{R}_{39}\right.$, feminino)

A criação de páginas web ou portais educativos é considerada uma boa prática pela possibilidade que oferece de publicar e difundir conteúdo de modo fácil e rápido, assim como por todos os links que se lhe podem associar e os tipos de formatos que permitem integrar. Essas atividades são reconhecidas pelo seu potencial didático por alguns dos alunos. Além disso, os participantes refletem preocupação pela escassa qualidade de conteúdos publicados e pela grande difusão on-line que alcançam. Como exemplo, veja-se o seguinte extrato:

Vou referir o aplicativo que mais me chamou a atenção até este momento, que foi a construção de uma página web. Numa disciplina criamos uma e apreciei essa atividade por ter relação com a nossa futura profissão. Aqui pudemos comentar sobre os temas que quiséssemos e também fazê-la mais aberta introduzindo perguntas, 
questionários para partilhar informação, fóruns para tratar de um tema a partir de um artigo publicado previamente por mim. $\left(\mathrm{R}_{41}\right.$, feminino)

\section{Utilidade ou beneficios associados às boas práticas com TIC}

Os alunos ligam as boas práticas com TIC a vantagens que atribuem aos dispositivos e aplicativos digitais. Referem uma ampla gama de benefícios: poupança de tempo, diversidade de recursos, facilidade de utilização dos aparelhos, melhoria das aprendizagens, aumento da motivação, maior comodidade (pois argumentam que evita as deslocações), dinamização nos debates, edição de conteúdos em diferentes formatos, partilha de recursos, acesso à internet e comunicação. Eles concentram nesses aspectos as utilidades ou os benefícios derivados das boas práticas com TIC, vinculando-os com diferentes dispositivos/ aplicativos ou ferramentas (tabela 2). Alguns aspectos estão diretamente focalizados no campo educativo, enquanto outros têm um caráter mais geral e são associados a âmbitos informais de aprendizagens e de lazer.

Tabela 2 - Benefício/utilidade das boas práticas com TIC

\begin{tabular}{|c|c|c|c|c|c|c|c|c|c|c|c|}
\hline \multirow[b]{2}{*}{$\begin{array}{l}\text { Dispositivo, aplicativo ou } \\
\text { ferramenta }\end{array}$} & \multicolumn{11}{|c|}{ Utilidade ou benefício } \\
\hline & 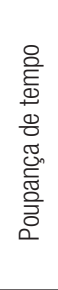 & 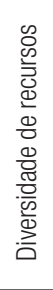 & 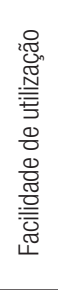 & 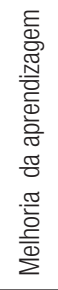 & 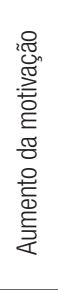 & 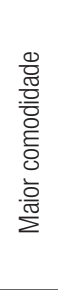 & 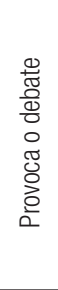 & 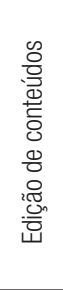 & 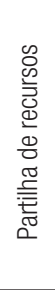 & 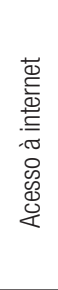 & 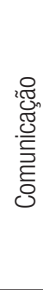 \\
\hline \multicolumn{12}{|l|}{ Computador } \\
\hline \multicolumn{12}{|l|}{ Smartphone } \\
\hline \multicolumn{12}{|l|}{ Aplicativos para smartphone } \\
\hline \multicolumn{12}{|l|}{ Livro eletrônico } \\
\hline \multicolumn{12}{|l|}{ Software informático } \\
\hline \multicolumn{12}{|l|}{ Quadro interativo } \\
\hline \multicolumn{12}{|l|}{ E-mail } \\
\hline \multicolumn{12}{|l|}{ Chat } \\
\hline \multicolumn{12}{|l|}{ Plataforma educativa } \\
\hline \multicolumn{12}{|l|}{ Vídeo digital } \\
\hline Aplicativos da web 2.0 & & & & & & & & & & & \\
\hline
\end{tabular}

Fonte: Dados da pesquisa.

No que se refere à promoção da comunicação, uma das alunas assinala o grande potencial das plataformas educativas, apresentando como exemplo o Moodle; ressalta que esse recurso reúne as possibilidades de uso da comunicação síncrona (chat) e assíncrona (fórum ou e-mail); também acrescenta que, no contexto educativo, o Moodle é de grande utilidade entre professores e alunos para tirar dúvidas, partilhar recursos, difundir avisos ou comunicados etc. Nesse sentido, indica uma estudante: 
0 Moodle tem as suas vantagens e os seus inconvenientes. A vantagem mais interessante desse recurso tecnológico, vejo-a na grande facilidade de comunicação que possibilita entre professores e alunos, permitindo armazenar muita informação que ajuda o aluno na sua aprendizagem. $\left(\mathrm{R}_{29}\right.$, feminino)

A utilização das TIC é reconhecida como uma mais-valia para o processo de ensino-aprendizagem, particularmente no que se refere ao aumento da motivação apoiada no quadro interativo. Como exemplo, apresenta-se o seguinte extrato:

Com o quadro interativo, que está na sala de informática, o professor utilizava-o para explicar-nos as práticas que tínhamos que fazer no computador. Assim, com a projeção do ecrã do computador nesse quadro, podíamos trabalhar de uma maneira muito mais fácil, interessante e lúdica. A aprendizagem é mais visual e rápida, já que através do quadro interativo podíamos ver cada passo a realizar para resolver as atividades propostas. Como anedota, dizer que todos queríamos trabalhar com ele, pintar, escrever, tocar no quadro... É algo novo que chama a atenção e te cativa. $\left(\mathrm{R}_{9}\right.$, feminino)

Sobre o acesso à internet através do computador de mesa e do portátil, os alunos manifestam que facilita a procura de informação que, de outra forma, permaneceria mais restrita ao uso das bibliotecas e dos livros. Os participantes afirmam que esse avanço fomenta a melhoria do processo formativo, principalmente pela rapidez e pela comodidade gerada. A esse respeito, narra uma participante:

Desde que se descobriu a internet, para todas ou pelo menos para uma grande maioria de pessoas, produziu-se uma mudança. Agora encontramos uma grande quantidade de informação na rede e as bibliotecas já não são o único lugar onde a consultamos. $\left(\mathrm{R}_{7}\right.$, feminino $)$

Alguns dos implicados no estudo também consideram que o alcance formativo das TIC se faz notar no que se refere à atividade de partilha de recursos. Desse modo, disversos alunos assinalam as redes sociais (Twitter e Facebook) como exemplos de bons cenários para se reunirem virtualmente com os colegas de turma e partilharem diferentes conteúdos. Consideram esses canais de comunicação como um modo de boas práticas com TIC fundamentalmente por permitirem o intercâmbio de recursos e de informação, assim como pelo diálogo que resulta de utilidade também no plano acadêmico. Uma aluna indica:

No Facebook, com os amigos ou colegas, costumamos criar grupos privados em que nos colocamos a par sobre alguns assuntos da turma: perguntas de exames, exercícios que há que fazer, datas limite de entrega. $\left(\mathrm{R}_{4}\right.$, feminino)

\section{Obstáculos atribuídos às boas práticas com TIC}

No que se refere aos obstáculos associados pelos alunos às boas práticas com TIC, há que indicar que consideram: custo econômico de alguns dispositivos, dificuldades técnicas e/ou de acesso que encontram, nível de formação que lhes exigem, distração que podem gerar, perda de privacidade, falta de respeito pelos direitos de autor, diminuição de contato presencial, perigos imprevistos e perda de tempo.

A relação detalhada sobre os obstáculos atribuídos a cada dispositivo/aplicativo ou ferramenta pelos participantes apresenta-se na tabela 3. Vê-se que focalizam a maior parte das problemáticas no computador (ainda que as concentrando no custo econômico e nas dificuldades técnicas) e nos aplicativos 
da web 2.0 (associando-as principalmente a deficiências técnicas e à escassa privacidade). Por outra parte, no livro eletrônico e no software informático, somente encontram a desvantagem do custo econômico.

Como se observa, os estudantes também atribuem alguma desvantagem às TIC, apesar de considerarem que formam parte das boas práticas. A modo de exemplo, mostra-se um excerto no qual se manifestam diferentes perigos associados à utilização das salas de chat:

0 uso do chat é uma boa prática porque facilita a partilha com os colegas e com os professores, mas também é muito fácil ser enganado. Também há que considerar que não permite expressar algumas emoções do mesmo modo que em pessoa. Além disso, é utilizado para abordagens de todo tipo e, em algumas ocasiões, pode deixar-se de lado a vida real para atender à da rede. $\left(\mathrm{R}_{11}\right.$, feminino $)$

A referência à perda de contato pessoal revelada por alguns alunos em relação à utilização das salas de chat e/ou do e-mail põe em evidência uma grande preocupação com esse aspecto.

Tabela 3 - Obstáculos gerados pelas boas práticas com TIC

\begin{tabular}{|c|c|c|c|c|c|c|c|c|}
\hline \multirow[b]{2}{*}{ Dispositivo, aplicativo ou ferramenta } & \multicolumn{8}{|c|}{ Obstáculo } \\
\hline & 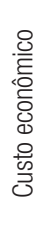 & 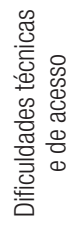 & 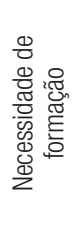 & 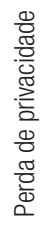 & 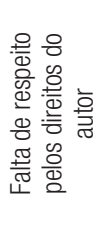 & 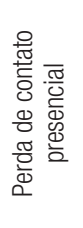 & 음 & $\begin{array}{l}\text { 을 } \\
\frac{E}{0} \\
\frac{0}{0} \\
\frac{\pi}{0} \\
\frac{0}{0} \\
0\end{array}$ \\
\hline \multicolumn{9}{|l|}{ Computador } \\
\hline \multicolumn{9}{|l|}{ Smartphone } \\
\hline \multicolumn{9}{|l|}{ Aplicativos para smartphone } \\
\hline \multicolumn{9}{|l|}{ Livro eletrônico } \\
\hline \multicolumn{9}{|l|}{ Software informático } \\
\hline \multicolumn{9}{|l|}{ Quadro interativo } \\
\hline \multicolumn{9}{|l|}{ E-mail } \\
\hline \multicolumn{9}{|l|}{ Chat } \\
\hline \multicolumn{9}{|l|}{ Plataforma educativa } \\
\hline \multicolumn{9}{|l|}{ Vídeo digital } \\
\hline Aplicativos da web 2.0 & & & & & & & & \\
\hline
\end{tabular}

Fonte: Dados da pesquisa.

\section{Extrapolação das boas práticas com TIC à futura profissão}

Quase todos os participantes veem utilidade nas TIC para a futura profissão. Entendem, ainda, que nos âmbitos de trabalho da educação social podem recorrer ao uso de boas práticas com TIC, principalmente para o desenvolvimento de atividades de: atenção a pessoas com necessidades especiais, prevenção ou recuperação de habilidades e destrezas (particularmente em pessoas idosas com Alzheimer) e comunicação/ partilha de informação entre diferentes profissionais e usuários.

Sobre a atenção a coletivos especiais, uma das alunas apresenta como exemplo o uso de software específico que permite a comunicação on-line no formato de som e imagem. Além disso, relembra a importância da videochamada em grupo. Entende que esse recurso, e 
particularmente a internet, promove o diálogo entre as pessoas com dificuldades físicas, no caso que aponta, quando apresentam problemas auditivos e estão dispersas geograficamente. Essa participante também manifesta que o recurso é uma alternativa valiosa para humanizar as relações, ter uma maior sensação de proximidade com outras pessoas e coletivos e incentivar que se envolvam em processos de aprendizagem. Com isso, considera que se põe em relevo o encurtar de barreiras associadas à distância física e às limitações nas atividades. A esse respeito, narra:

Uma especialista falou de programas para telemóvel nos quais te podem ver e podes ver, como é o caso do Skype através do computador. Entre a comunidade surda costuma-se usar o ooVoo, que se trata de videoconferência em grupo, o que nos resultou em grande interesse já que nós, no futuro, para nos comunicarmos com pessoas surdas, teríamos que usá-lo. $\left(\mathrm{R}_{50}\right.$, feminino)

No âmbito da prevenção ou da recuperação de habilidades, destrezas e competências cognitivas, os alunos assinalam as TIC para exercitar a memória, vendo-as como uma boa prática. Alguns participantes consideram que o contributo principal das TIC está no uso de cenários apelativos e dinâmicos, assim como na grande diversidade de recursos gratuitos disponíveis na internet. A partir das aplicações desses recursos, referem que os educadores sociais poderão responder mais facilmente às exigências específicas de cada contexto de trabalho. De modo ilustrativo, veja-se o seguinte extrato:

Falando de outras experiências pessoais com meninos autistas, eu posso referir-me às minhas práticas com eles mediante o uso de pictogramas no computador. Esse material resulta-lhes muito motivador $\mathrm{e}$ favorece suas aprendizagens. $\left(R_{31}\right.$, feminino)

Um aluno descreve a criação de um blog e considera-o muito interessante para promover o intercâmbio de conteúdo e/ou a partilha de informação dentro de uma comunidade educativa. Nesse caso, trata-se de uma atividade enquadrada no âmbito escolar, juntamente com a troca de informação e interação entre pai/mãe e professor/a. Um participante indica:

Entre os projetos desenvolvidos que conheço está a criação de um blog dedicado às famílias, o orientablog, onde podem expor de maneira conjunta e organizada os temas que lhes resultam em interesse ou as preocupações que têm os pais e as mães dos alunos. $\left(\mathrm{R}_{26}\right.$, masculino)

\section{Conclusão e discussão}

É de salientar que o simples uso das TIC é associado pelos alunos às boas práticas, colocando em relevo os aspectos de tipo pragmático, sem questionar sua combinação com as metodologias didáticas de caráter inovador. Para Dalsgaard (2006), a maior parte dos recursos digitais possibilita solucionar problemas relacionados com a atividade educativa, com o trabalho ou com a vida pessoal, supondo um aliciante. As boas práticas com TIC são vinculadas pelos participantes essencialmente ao uso dos computadores, à comunicação, aos dispositivos, ao software e aos aplicativos mais inovadores do mercado. Consideram os referidos recursos como meios para o desenvolvimento de atividades, em geral, interessantes e úteis.

Como benefícios atribuídos às boas práticas com TIC, assinalam a economia de tempo, a diversidade de recursos, as facilidades para a utilização, o baixo custo econômico de alguns dispositivos e aplicativos, as melhoras propiciadas na aprendizagem, a edição e difusão de conteúdos em diferentes formatos, a partilha de recursos, o acesso à internet e à comunicação. Guimarães (2007) também reconhece vantagens nesses aspectos por facilitarem a dinamização do trabalho colaborativo em rede, já que as TIC permitem o 
manejo de grande volume de dados em diversos formatos, com independência física e temporal. Dessa forma, é compreensível e desejável que se potencie o uso dos recursos on-line para promover também a aprendizagem ubíqua a partir de novos paradigmas pedagógicos.

Como obstáculos associados pelos participantes à utilização das boas práticas com TIC, são de destacar as dificuldades técnicas que eles encontram. Além disso, eles mencionam necessidades de formação, a distração que se pode gerar, a perda de privacidade e de tempo, o deterioramento do contato presencial, os perigos da rede e o elevado custo de alguns dispositivos. Vajargah, Jahani e Azadmanéh (2010) afirmam a importância do acompanhamento e da interação oferecida pelos professores para que o alcance formativo responda às expetativas dos alunos.
Ainda que se trate de alunos que se incorporaram recentemente aos estudos universitários, com acerto e de forma fundamentada, já extrapolam a utilização de alguns aparelhos de TIC às diferentes áreas de trabalho da profissão. Os participantes reconhecem principalmente a utilidade desses recursos no âmbito da educação social para a atenção a coletivos com algum tipo de deficiência ou limitação, na comunicação/partilha de conteúdos entre diferentes usuários de uma comunidade educativa. De fato, Bruno et al. (2006) têm apresentado evidências da importância da utilização das TIC como recursos educativos. Sustentam, ainda, que tais tecnologias possuem um grande potencial capaz de promover a melhoria da qualidade da formação, nomeadamente na utilização de software específico para pessoas que apresentam dificuldades de aprendizagem.

\section{Referências}

AREA, Manuel; SAN NICOLÁS, María Belén; FARIÑA, Elena. Buenas prácticas de aulas virtuales en la docencia universitaria semipresencial. Teoría de la Educación: Educación y Cultura en la Sociedad de la Información, Salamanca, v. 11, n. 3, p. 7-31, 2010. Disponível em: <http://gredos.usal.es/sspui/bitstream/10366/72859/1/BUENAS_PRACTICAS_DE_AULAS_VIRTUALES_ EN_.pdf>. Acesso em: 11 maio 2012.

BATES, Tony. Más allá del teclado. In: EPPER, Rhonda; BATES, Tony (Coords.). Enseñar al profesorado como utilizar la tecnología: buenas prácticas de instituciones líderes. Barcelona: Editorial UOC, 2004. p. 171-182.

BRUNO, Alicia et al. Análisis de un tutorial inteligente sobre conceptos lógico-matemáticos en alumno con Síndrome de Down. Revista Latinoamericana de Investigación en Matemática Educativa, México, v. 9, n. 2, p. 211-226, 2006. Disponível em: $<$ http://www.scielo.org.mx/scielo.php?pid=S1665-24362006000200003\&script=sci_arttext >. Acesso em: 30 abr. 2013.

CANALES, Roberto; MARQUÉS, Pere. Factores de buenas prácticas educativas con apoyo de las TIC: análisis de su presencia en tres centros educativos. Educar, Barcelona, v. 39, p. 115-133, 2007.

COELHO, Bárbara. Políticas de informação, as tecnologias de informação e comunicação e a participação no âmbito da sociedade da informação: enfoque na inclusão digital do global ao local. Transinformação, Campinas, v. 22, n. 1, p. 47-60, 2010.

COELHO, Bárbara; ROSÁRIO, Raquel; FERREIRA, Henriette. A condição estruturante das tecnologias nas relações sociais: potencialidades na interlocução entre biblioteca e usuário. Informação \& Sociedade: Estudos, Paraíba, v. 22, n. 3, p. 25-31, 2012.

COLL, César; MAURI, Teresa; ONRUBIA, Javier. Análisis de los usos reales de las TIC en contextos educativos formales: una aproximación socio-cultural. Revista Electrónica de Investigación Educativa, Cáceres, v. 10, n. 1, p. 1-18, 2008. Disponível em: $<$ http://redie.uabc.mx/index.php/redie/article/view/177/307>. Acesso em: 30 abr. 2013.

DALSGAARD, Christian. Social software: e-learning beyond learning management systems. European Journal of Open, Distance and E-learning, Castlethorpe, v. 2, p. 1-7, 2006.

DE PABLOS, Juan; JIMÉNEZ, Rocío. Buenas prácticas con TIC apoyadas en las políticas educativas: claves conceptuales y derivaciones para la formación en competencias ECTS. Revista Latinoamericana de Tecnología Educativa, Cáceres, v. 6, n. 2, p. 15-28, 2007. Disponivel em: <http://campusvirtual.unex.es/cala/editio/index. php?journal=relatec\&page=article\&op=view\&pat h]=345\&path[=293>. Acesso em: 12 fev. 2012.

DÍEZ GUTIÉRREZ, Javier. Modelos socioconstructivistas y colaborativos en e luso de las TIC en la formación inicial del profesorado. Revista de Educación, Madrid, v. 358, p. 175-197, 2012. Disponível em: <http://www.educacion.gob.es/dctm/revista-deeducacion/articulos-re358/re35809.pdf?documentld=0901e72b8128205e >. Acesso em: 19 mar. 2012. 
DIRCKINCK-HOLMFELD, Lone; LORENTSEN, Annette. Transforming university practice through ICT-integrated perspectives on organizational, technological, and pedagogical change. Interactive Learning Environments, Londres, v. 11, n. 2, p. 91-110, 2003.

FELIZ, Tiberio. Análisis de contenido de la comunicación asíncrona en formación universitaria. Revista de Educación, Madrid, v. 358, p. 282-309, 2012. Disponível em: <http://www.educacion.gob.es/dctm/revista-de-educacion/articulos-re358/re35814.pdf? documentld=0901e72b8128267e $>$. Acesso em: 14 maio 2012.

FERREIRO, Emilia. Alfabetización digital: ¿De qué estamos hablando? Educação e Pesquisa, São Paulo, v. 37, n. 2, p. 423-438, 2011. FLICK, Uwe. Uma introdução à pesquisa qualitativa. Porto Alegre: Bookman, 2005.

GONZÁLEZ CUBILLÁN, Lesbia. Estudio de casos bajo el enfoque transdisciplinar. Multiciencias, Zulia, v. 9, n. 3, p. 303-312, 2009. Disponível em: <http://revistas.luz.edu.ve/index.php/mc/article/viewFile/3708/3604>. Acesso em: 13 jun. 2012.

GUIMARÃES, Jane. Educação, globalização e educação à distância. Revista Lusófona de Educação, Lisboa, v. 9, p. 139-158, 2007. Disponível em: <http://www.scielo.oces.mctes.pt/pdf/rle/n9/n9a09.pdf>. Acesso em: 14 jul. 2012.

HERNÁNDEZ, Roberto; FERNÁNDEZ, Carlos; BAPTISTA, Pilar. Metodología de la investigación. México: McGraw-Hill, 2006.

HONG, Kian-Sam; SONGAN, Peter. ICT in the changing landscape of higher education in Southeast Asia. Australasian Journal of Educational Technology, Tugun, v. 27, n. 8, p. 1276-1290, 2011. Disponível em: <http://www.ascilite.org.au/ajet/ajet27/hong. pdf>. Acesso em: 12 maio 2012.

LECOMPTE, Margaret; PREISSLE, Judc. Ethnography and qualitative design in educational research. San Diego: Academic Press, 1993.

MOLINA, Alfonso. The digital divide: the need for a global e-inclusion movement. Technology Analysis \& Strategic Management, Londres, v. 15, n. 1, p. 137-152, 2003.

RICOY, María Carmen; SEVILLANO, María Luisa; FELIZ, Tiberio. Competencias necesarias para la utilización de las principales herramientas de Internet en la educación. Revista de Educación, Madrid, v. 356, p. 483-507, 2011. Disponível em: <http://www.educacion.gob.es/ dctm/revista-de-educacion/articulosre356/re35620.pdf?documentld=0901e72b81203170 > . Acesso em: 2 mar. 2012.

SALINAS, Jesús. Los recursos didácticos y la innovación educativa. Comunicación y Pedagogía, Barcelona, v. 200, p. 36-39, 2004.

SANTOS, Gilberto Lacerda dos. Ensinar e aprender no meio virtual: rompendo paradigmas. Educação e Pesquisa, São Paulo, v. 37, n. 2, p. 307-320, 2011.

SARRADO, Juan José; PRUNA, Mónica; LÓPEZ, Pau. El cuento como entorno de crecimiento sociopersonal en la intervención psicopedagógica con población adolescente infractora. Estudios Sobre Educación, Navarra, v. 13, p. 57-85, 2007. Disponível em: <http://dspace.unav.es/dspace/bitstream/10171/9045/1/Ed\%2013.pdf>. Acesso em: 11 jul. 2012.

STAKE, Robert. A arte de investigação com estudos de caso. Lisboa: Fundação Gulbenkian, 2007.

VAJARGAH, Kourosh Fathi; JAHANI, Sheida; AZADMANÉH, Nahid. Application of ICTS in teaching and learning at university level: the case of Shahid Behéhti University. Turkish Online Journal of Educational Technology, Sakarya, v. 9, n. 2, p. 33-39, 2010. Disponível em: <http://www.tojet.net/articles/v9i2/924.pdf>. Acesso em: 10 jul. 2012.

VANDERLINDE, Ruben; VAN BRAAK, Joan; DEXTER, Sara. ICT policy planning in a context of curriculum reform: disentanglement of ICT policy domains and artifacts. Computers \& Education, Amsterdam, v. 58, n. 4, p. 1339-1350, 2012.

VICENTINI, Maria José. Impacto das tecnologias de Informação e comunicação: cultura digital e mudanças sócio-culturais. Informação \& Sociedade: Estudos, Paraíba, v. 22, n. 2, p. 13-25, 2012.

YANG, Hao. ICT in English schools: transforming education? Technology, Pedagogy and Education, Londres, v. 21, n. 1, p. 101-118, 2012.

YIN, Robert. Estudo de caso: planejamento e métodos. Porto Alegre: Bookman, 2005.

Recebido em: 05.05.2013

Aprovado em: 27.06.2013

María Carmen Ricoy é doutora com prêmio extraordinário (2001) e professora titular na Universidade de Vigo (Espanha). Atua fundamentalmente na área de novas tecnologias aplicadas à educação.

Maria João V. S. Couto é doutoranda da Universidade de Vigo (Espanha) e bolsista da Fundação para a Ciência e a Tecnologia (Portugal). Atua na linha de pesquisa de novas tecnologias aplicadas à educação matemática e como professora convidada. 